\title{
Editorial 21/2
}

\section{Hubert Österle • Rainer Alt • Karen Heyden}

Published online: 27 May 2011

(C) Institute of Information Management, University of St. Gallen 2011

Dear Readers of Electronic Markets,

Welcome to this issue of Electronic Markets which is a special issue on "Information and Data Quality in Networked Business". As you will see, this topic has become an important concept for Networked Business and Electronic Markets in particular. The more independent businesses collaborate to attain complex solutions for their customers, the more we face challenges of heterogeneous information structures and process designs. These semantic issues have the power to enable, but also to inhibit Business Networking. We are therefore to our guest editors Boris Otto, Yang W. Lee and Ismael Caballero Muñoz-Reja who made this special issue possible. They were supported by many reviewers who invested significant effort to develop the four articles included in this special issue. All contributions are introduced by the guest editors in their separate editorial.

In addition to these submissions, this issue also comprises a position paper on "Information and Data Quality in Business Networking: A Key Concept for Enterprises in its Early

H. Österle $(\bowtie)$

Institute of Information Management, University of St. Gallen, Müller-Friedberg-Strasse 8,

St. Gallen 9000, Switzerland

e-mail: hubert.oesterle@unisg.ch

R. Alt $\cdot$ K. Heyden

Information Systems Institute, University of Leipzig,

Grimmaische Str. 12,

Leipzig 04109, Germany

R. Alt

e-mail: rainer.alt@uni-leipzig.de

K. Heyden

e-mail: heyden@wifa.uni-leipzig.de
Stages of Development". Here, the three guest editors present an analysis on how issues of data and information quality as well as Business Networking have been discussed in the literature and which questions arise for the future. As you will see, there is a broad body of knowledge available on single aspects which reflect the significance and the complexity of data and information quality issues in Business Networking. However, the analysis convincingly substantiates the low maturity of the field and points at the need for an overall concept. We hope you find this position paper stimulating for your research and would be happy to receive your opinions.

Finally, two organizational aspects should be mentioned. First, each paper submitted as general research will be assigned a responsible Associate Editor for the entire "life cycle" of the papers at Electronic Markets in the future. This includes the communication with the authors as well as the reviewers with the ultimate goal to safeguard substantial feedback to the authors either when papers are rejected or returned for revisions, but also to develop a paper until publication. We hope that this contributes to the quality of papers in Electronic Markets and always appreciate your suggestions for improvement. Second, the journal website (www.electronicmarkets.org) has been reorganized in order to facilitate the navigation and the retrieval of the desired content. In the future, the main menu contains 'About EM, 'Team', 'Ranking', 'Articles' and 'Authors' as well as information for potential 'Guest Editors'. All call for papers and news are available in separate portlets. Of course, we are thankful for feedback in this regard as well.

Best regards,

Hubert Österle

Rainer Alt

Karen Heyden 